\title{
(F)ailing women in psychiatry: lessons from a painful past
}

Cite as: CMAJ 2018 May 22;190:E624-5. doi: 10.1503/cmaj.171277

CMAJ Podcasts: author interview at https://soundcloud.com/cmajpodcasts/171277-medsoc

n August 2017, data released by the US National Center for Health Statistics, a government agency affiliated with the US Centers for Disease Control and Prevention, made the evening news, igniting an urgent conversation about women's mental health. The data, spanning 1975 to 2015 , showed that suicide rates among women aged 15 to 19 years had hit a 40-year high. ${ }^{1}$ Equally alarming? Between 2007 and 2015 , suicide rates among this female demographic had doubled in the United States. ${ }^{1}$ As medical professionals seek to understand possible causes for these disturbing shifts - cyberbullying and Netflix's controversial series, 13 Reasons Why, have already been identified - we urge the medical community to take a broader view that includes history. Looking to the past will not reveal straightforward answers, but it can elucidate patterns to better inform how we understand the current crisis and effect meaningful change.

The history of psychiatry is replete with examples of poor outcomes for women in need, often women who sought medical help. Lobotomies are an extreme but illustrative example. Ask medical students about the lobotomy's history and you will probably hear a narrative similar to that of the US Public Broadcasting Service's (PBS) acclaimed 2008 documentary, The Lobotomist. In the 1940s, when psychiatric asylums were understaffed, underfunded and overcrowded, neuropsychiatrist Dr. Walter Freeman popularized psychosurgery to "liberate" patients from the hopelessness of therapeutic nihilism and the probability of lifelong custodial care. The most frequently performed lobotomy was the transorbital. A physician guided a long cannula (Freeman first used an ice pick) through the patient's eye socket and into the brain and then moved it left to right - a motion some have compared with that of a windshield wiper to sever the patient's lower frontal lobes. In 1937, Freeman and surgeon James Watts published on the surgery's benefits, based on a case study of six patients with psychiatric symptoms. They credited the surgery for alleviating patients' symptoms: "insomnia, nervous tension, apprehension and

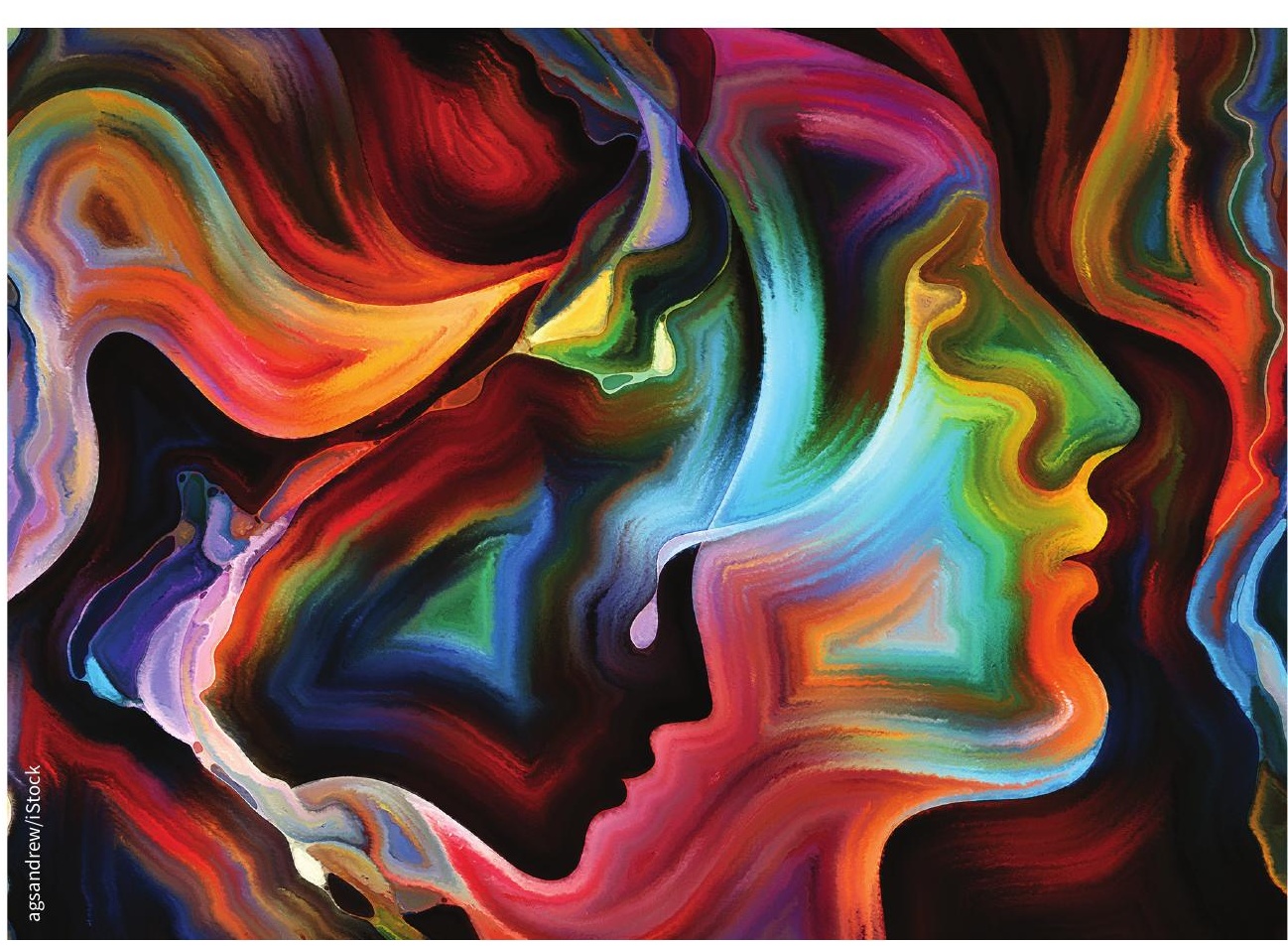

anxiety."2 They identified drawbacks, too. Patients were "more comfortable," but markedly more docile. "Every patient loses something by this operation," they conceded. "Some spontaneity, some sparkle." All the same, scientific acceptance of lobotomies grew. In 1949, its putative founder was awarded a Nobel Prize. By 1952, an estimated 50000 patients in the United States and Canada had been lobotomized.
What the documentary omits is that most lobotomized patients were women, although most institutionalized patients at the time were men. This gaping disparity, noted by scholars, is made more troubling by the general silence surrounding it today. ${ }^{3}$ Yet the disparity has been in plain view from the start. Five of the six patients in the case study by Freeman and Watts were women 
therapeutic success in the annals of history. ${ }^{2}$ By $1942,75 \%$ of the lobotomies Freeman and Watts had performed were on women.

It wasn't just Freeman and Watts. A comprehensive survey of US psychiatric facilities between 1949 and 1951 found that most patients lobotomized by doctors were women. ${ }^{4}$ At a time when women were expected to be calm, cooperative and attentive to domestic affairs, definitions of mental illness were as culturally bound as their treatments. A surgery that rendered female patients docile and compliant, but well enough to return to and care for their homes, had many proponents before the drug chlorpromazine, the first "major" tranquilizer, became available in 1954 .

Chlorpromazine's success launched our modern psychopharmcologic era, anointing drugs as the treatment of choice in asylum and outpatient psychiatry. Tellingly, prescribing patterns reinforced earlier tropes. By 1968, the "minor" tranquilizer Valium (diazepam), marketed as an antidote for socially dysfunctional women - the excessively ambitious, the visually unkempt, the unmarried and the menopausal misfits - was the best-selling drug in the world as well as one prescribed overwhelmingly to women. ${ }^{5}$

The disproportionate use of lobotomies and tranquilizers by doctors as therapies for female patients exemplify how gender bias has shaped twentieth-century medicine, but is there evidence that bias influences physician decision-making today? Unfortunately, yes. Recent studies of "implicit bias," loosely defined as a preference an individual has but doesn't consciously recognize, show that medical practitioners are as susceptible to the same biases as their nonphysician peers. Although this finding is not surprising - humans cannot opt out of their culture to be objective - it is problematic in medicine for several reasons.

One reason is the capacity to harm. Practitioners treat patients who vary by age, weight, sex, ethnicity, blood pressure and other variables. They know a patient is never simply one of these categories. But when a physician reduces the multifaceted patient to a prejudicial category, and acts on implicit bias, the patient's well-being may suffer. Implicit biases involving race, ${ }^{6}$ weight $^{7}$ and gender ${ }^{8}$ have been well documented. In one study of pain management in an urgent care setting, and after control- ling for age, race, class and pain scores, women were $13 \%$ to $25 \%$ less likely than men to receive opioid analgesia and waited longer to see a doctor, too. ${ }^{9}$

A related problem is how to discuss implicit bias within the frame of today's evidence-based medicine. A physician's authority stems partly from a shared understanding that a doctor's personal views will be checked by the collective weight of metaanalyses of double-blinded randomized controlled trials, or best-practice guidelines based on aggregate data. Evidence-based medicine roots physicians in the objective soil of science. Implicit bias highlights their subjectivity and individual variability. ${ }^{9}$

Medical practitioners continue to reflect and reinforce the prejudices of our time. In this sense, we share more with those in the age of lobotomy than we wish to acknowledge. Even the term "evidence-based medicine" tacitly suggests a time when medicine was practised without it.

What will historians of the future say about our present? Are we undertreating women's pain because we categorize women as emotive? Are we ignoring a woman's psychological anguish because the way she communicates it deviates from an expected script? Do we discount the suicidal ideation of adolescent women because data show that women are more likely to consider suicide but less likely to follow through ${ }^{10}$ The challenge for today's medical practitioners is to be as scrupulous in identifying our biases toward patients as we are when examining clinical evidence. We must reevaluate our penchant for categories and recognize their human costs. Is labelling the suicide crisis "female" the best way to save lives, when the data released in August $^{1}$ show that suicides among young men are also increasing? Whose bias has branded these deaths insufficiently newsworthy?

What makes medical history meaningful is not the opportunity to review the past, skip the unflattering bits and celebrate how far medicine has come. Those triumphal tales abound, but more can be learned from a critical-but-honest appraisal that enjoins us to acknowledge a simple precept: medicine is a human endeavour. Its history cannot, and should not, be detached from the perspectives of those who practise it. That history is messy: replete with biases, mistakes and assumptions that deserve a care- ful look, as do our own. Lobotomization of women, prescription disparities, changing suicide demographics: each example is best understood in a historical context bounded by time and place. Collectively, they remind us that definitions of medical maladies and therapeutic success are constantly being reinterpreted and revised. That immutability is what gives medical history, in the words of Jacalyn Duffin, its intrinsic "timelessness." Although this unfiltered view of medicine's past may be unsettling, it also provides us with possibilities for change. The past needn't be prologue. If modern medicine is, to some extent, of our own making, then it is also within our power to remake it.

\section{Andrea Tone PhD}

Social Studies of Medicine, McGill

University, Montréal, Que.

\section{Mary Koziol B.Arts Sc}

Faculty of Medicine, McGill University, Montréal, Que.

\section{References}

1. Scutti S. Suicide rate hits 40-year peak among older teen girls in 2015. CNN 2017 Aug. 3. Available: www. cnn.com/2017/08/03/health/teen-suicide-cdc-study -bn/index.html (accessed 2017 Aug. 3).

2. Freeman W, Watts JW. Prefrontal lobotomy in the treatment of mental disorders. South Med J 1937;30: 23-31.

3. Braslow JT. Mental ills and bodily cures: psychiatric treatment in the first half of the twentieth century. Berkeley: University of California; 1997:152-70.

4. Kramer M. The 1951 survey of the use of psychosurgery. In: Mettler Fa, Overholser W, Proceedings of the Third Research Conference on Psychosurgery. Public Health Service Publication 221. Washington (DC): Government Printing Office; 1954:162.

5. Tone A. The age of anxiety: a history of America's turbulent affair with tranquilizers. New York: Basic Books; 2009:152-8.

6. Sabin JA, Nosek BA, Greenwald AG, et al. Physician implicit and explicit attitudes about race by MD gender, race and ethnicity. J Health Care Poor Underserved 2009;20:896-913.

7. Teachman BA, Brownell K. Implicit anti-fat bias among health professionals: Is anyone immune? Int J Obes Relat Metab Disord 2001;25:1525-31.

8. Hamberg K, Risberg G, Johansson EE, et al. Gender bias in physicians' management of neck pain: a study of the answers in a Swedish national examination. J Womens Health Gend Based Med 2002;11: 653-66.

9. Chen EH, Shofer FS, Dean AJ, et al. Gender disparity in analgesic treatment of emergency department patients with acute abdominal pain. Acad Emerg Med 2008;15:414-8.

10. Canetto SS, Sakinofsky I. The gender paradox in suicide. Suicide Life Threat Behav 1998;28:1-23.

11. Duffin J. Clio in the clinic: history in medical practice. New York: Oxford University Press; 2005.

This article has been peer reviewed. 